\title{
Thermal imaging for detecting temperature changes within the rheumatoid foot
}

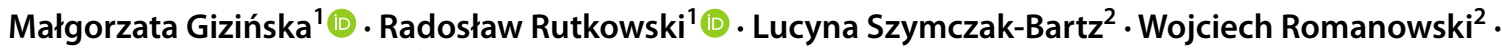 \\ Anna Straburzyńska-Lupa ${ }^{1,2} \mathbb{C}$
}

Received: 25 March 2019 / Accepted: 4 April 2020 / Published online: 27 April 2020

(c) The Author(s) 2020

\begin{abstract}
The study reports the development of a thermal imaging method suitable for the screening and differentiation of joint inflammation in the rheumatoid foot of patients in comparison with the control group of healthy participants. The study included 81 patients, with rheumatoid arthritis (RA), and 39 healthy volunteers without any signs or symptoms of inflammation. The feet joints were examined by ultrasonography, and the surface temperature of the dorsal side of the foot was measured using a thermovision camera. Significant differences in mean temperatures between the study group and the control group were found. At the same time, there were no statistically significant differences between the mean temperatures in the left and right foot in any of the designated regions in the study and control group. The comparison of average temperatures of joints with or without inflammation, according to ultrasonography, did not show significance except for two joints. Despite the lack of statistical differences in the recorded temperatures, changes in the form of spikes, hot spots, and gradation of the temperatures during screening were observed. Screening analysis of the temperature distribution of the foot can aid in the diagnosis of RA and in the evaluation of the development of the disease. Additional studies must be conducted to confirm the results of this study.
\end{abstract}

Keywords Thermal imagine $\cdot$ Screening $\cdot$ Rheumatoid arthritis $\cdot$ Rheumatoid foot $\cdot$ Inflammation

Małgorzata Gizińska and Radosław Rutkowski are co-first authors and also contributed equally to this work.

Małgorzata Gizińska

gizinska@awf.poznan.pl

Radosław Rutkowski

rts.rutkowski@gmail.com

Lucyna Szymczak-Bartz

lucyna.szymczak-bartz@wp.pl

Wojciech Romanowski

romanowski@reumatologia.srem.net

Anna Straburzyńska-Lupa

a.straburzynskalupa@gmail.com

1 Department of Physical Therapy and Sports Recovery, Poznan University of Physical Education, Królowej Jadwigi str. 27/39, 61-871 Poznan, Poland

2 Rheumatological Centre in Śrem, Mickiewicza str. 95, 63-100 Srem, Poland

\section{Introduction}

Rheumatoid arthritis (RA) is an autoimmune systemic connective tissue disease; the etiology of RA has not been fully elucidated [1]. Factors such as genetic, environmental, infectious and autoimmune disorders play an important role in the etiopathogenesis of RA. Many types of immune cells and their cytokines, proteinases and growth factors mediate inflammation, joint destruction, and systemic complications that lead to disability and premature death. The heterogeneous character of the disease results in impossibility to predict its progress.[2, 3]. This disease has a chronic course with periods of exacerbation and remission. RA is characterized by nonspecific inflammation of the symmetrical joints and the occurrence of joint swelling, joint tenderness, and destruction of the synovial joint [1].

One of the major problems that occur in the RA patients is foot complaint. Approximately, $90 \%$ of the patients complain of pain in the feet, which affects various aspects of daily activities. However, the severity of pathological changes in the feet varies depending on the clinical form, 
dynamics of the disease, and the disease duration [4, 5]. The inflammation causes pain, swelling, and hypertrophy of the synovial membrane of the joint, leading to structural changes and deformities, such as subluxation of the metatarsophalangeal (MTP) joints, toe deformities, and valgus alignment of the rear foot [4]. Despite the adverse effects of the pain and impairment in the structure and function of the foot, leading to disability in activities of daily living, as experienced by the patients, there is limited available literature on the rheumatoid foot.

Various imaging techniques, such as X-ray, ultrasound, magnetic resonance imaging (MRI), and classical and electron microscopy, can visualize structural changes, even in the early stages of disease; however, the changes in the temperature of the tissues cannot be visualized.

Medical thermal imaging provides information on the functioning of the superficial dermal macrocirculation that is affected by local inflammatory processes [6-8]. The pathological changes can be manifested by the heat radiation of tissues and organs, which transposes to the surface regions [9]. Superficial temperature may increase or decrease due to the reduction or deterioration of inflammation. These subtle temperature changes can be recorded by infrared thermography; these changes can then be objectively evaluated after pharmacological, physical, or surgical treatment [10].

Thermography is a non-invasive non-contact method of visualizing superficial infrared radiation of the object using a thermal imaging camera. Thermal images can be recorded rapidly and hygienically, without any adverse effects on the human body, and the process is inexpensive. To obtain a suitable image of the temperature distribution, the conditions and protocols of the method must be strictly followed $[10,11]$.

Many authors have reported that the use of thermovision techniques is a very useful tool in the examination of patients. Thermovision techniques have been used for various purposes in medicine, including clinical testing of drugs [12], assessment of vascular reactions in hands [13-18], diagnosis of Raynaud's syndrome [19, 20], evaluation of observational changes in osteoarthritis $[9,15]$, detection of different kinds of tumors [21, 22], and assessment of the skin condition in diabetic feet $[23,24]$.

In rheumatology, infrared imaging is used to detect the increased temperature associated with inflammation or decreased temperature caused by nociceptive afferentation or the obstruction of vessels. This method can also be used to monitor temperature changes after pharmacotherapy and other therapeutic methods of treatment and to observe micro- and macrocirculation [10].

There is little research on the possibility of using thermovision for the diagnosis of inflammatory changes in the foot; the results of these works are inconclusive. The use of thermal imaging for the screening and differentiation of joint inflammation has not been assessed in rheumatoid foot.

The aim of this study was to investigate the usefulness of using thermal imaging in detection pathological changes of the foot in RA patients compared with the control group of healthy participants and for screening temperature distribution of the foot.

\section{Materials and methods}

The study was conducted on 81 patients, aged $57.4 \pm 10.47$ years, diagnosed with RA according to the American College of Rheumatology (ACR) criteria [1], who were inpatients treated at the Rheumatology Department and 39 healthy volunteers without any signs or symptoms of impairment in the musculoskeletal system.

All patients satisfied the following inclusion criteria: RA classified according to the ACR criteria defined in 2010 [1], the presence of pain and stiffness of the foot in the preliminary, and provision of consent to the study. Patients with large deformations of the feet and cognitive, proprioceptive, and sensory impairments, those with foot fractures, and those who underwent surgery in the last six months were excluded from this study.

This study was approved by the Research Ethics Committee at Poznan University of Medical Sciences under the Protocol Number 183/14. All the participants provided informed consent.

At first, patients were examined by ultrasonography, which was performed using an Esaote, MyLab Twice witch 6-18 MHz transducer. Ultrasonography was performed by rheumatologist, who routinely performs ultrasound tests, on the dorsal side of the foot and also involved the 1-5 MTP joints. During the test, the foot was in a neutral position. The rheumatologist examined the joints for the presence or absence of signs of inflammation in the form of a synovitis and swelling. The presence of inflammation in the joint was defined as minimal hypertrophy of the synovium or/and slightly increased vascularization $[25,26]$.

The next day, thermal imaging was performed. On the day of the research, patients were not allowed to smoke, drink alcohol or coffee and use other stimulants and drugs except for drugs prescribed earlier by their specialist which were used in a consistent dosage. Moreover, undertaking intensive physical activity and participating in other physical treatments was forbidden. In addition, patients were informed about the need for adaptation process by stabilization temperature after removing clothes in a controlled environment before measurement for $20 \mathrm{~min}$. The surface temperature of the feet was measured by the thermovision camera ThermaCAM SC640 (Flir) according to the guidelines provided by the European Association of Thermology 
[27]. The emissivity was set to 0.98 . Calibration of the camera always took at least $20 \mathrm{~min}$ before the first measurement. The imaging wastaken in the morning by the same researchers. Thermography was performed under certain conditions, namely, in a draught-free room, shielded from direct sunlight, with the temperature being at maintained $21^{\circ} \mathrm{C}$ and humidity $40 \pm 10 \%$. The camera was positioned on a tripod $50 \mathrm{~cm}$ above the feet in a natural position, perpendicular to them. Images of the dorsal side of the feet were taken and used for analysis.

Thermographic images were processed according to the rules of the Glamorgan Protocol [27] and modified to set the required regions of interest. There were seven regions of interests (ROI) manually specified from all the feet of the patients. The largest polygon area ROI 1 was designated by the outlines that were tangential to the foot, and the proximal end of this region showed a horizontal line aligned with the tip of the navicular bone. The second area was reduced by not including the metatarsal part and surface of the toe. The contour of ROI 2 was defined in the shape of a polygon adjacent to the edge of the MTP joints and the horizontal line was at a tangent to the top of first and fifth MTP joint. ROI I-V were marked as circles, and the outlines of their shape were adjacent to the edges of the MTP joints (Fig. 1).
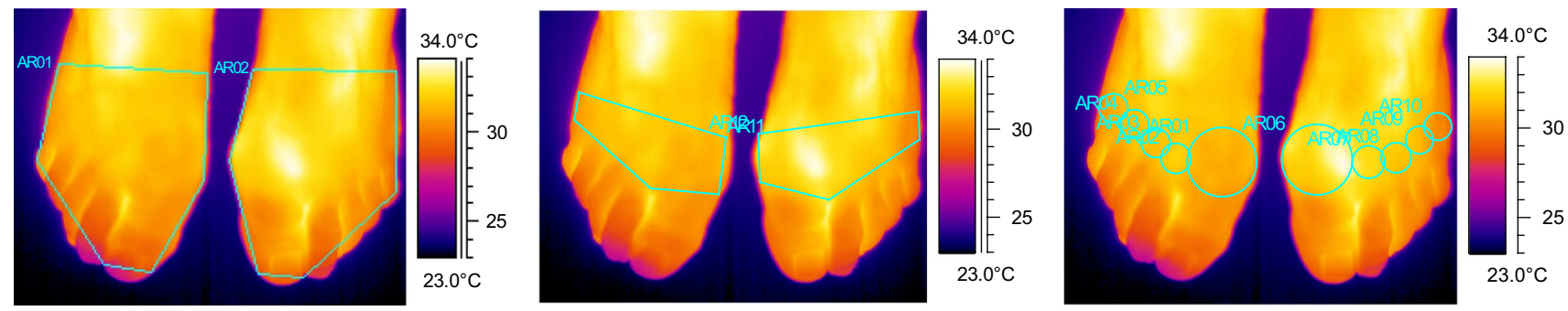

Fig. 1 Graphic representation of the seven regions of interest. a ROI 1-large area, b ROI 2-small area, $\mathbf{c}$ ROI I-V—MTP joints
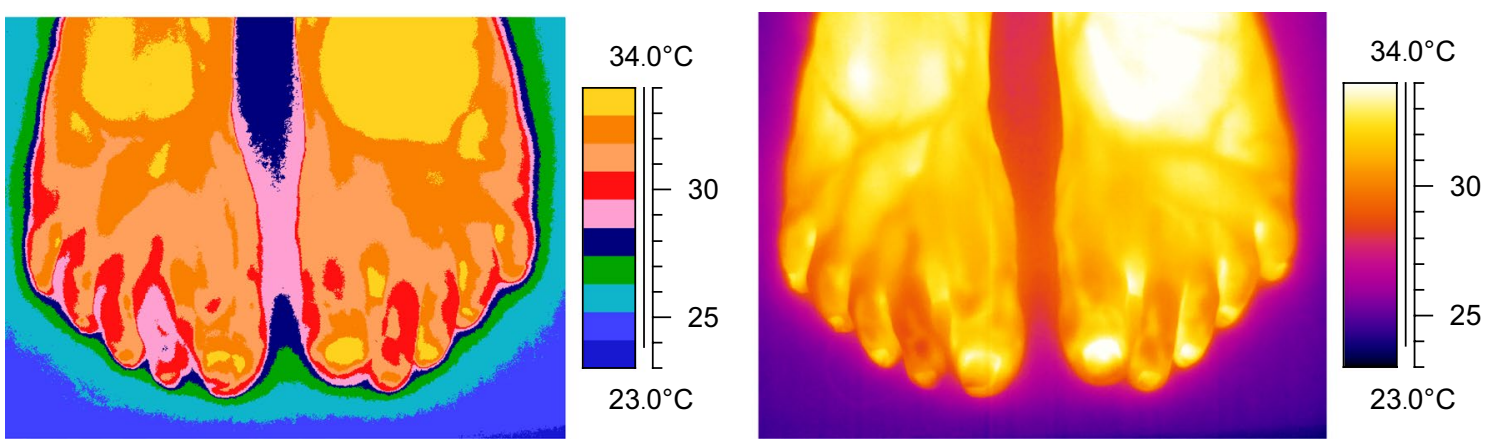

Fig. 2 Temperature distribution in the medical and standard palette of the rheumatoid foot
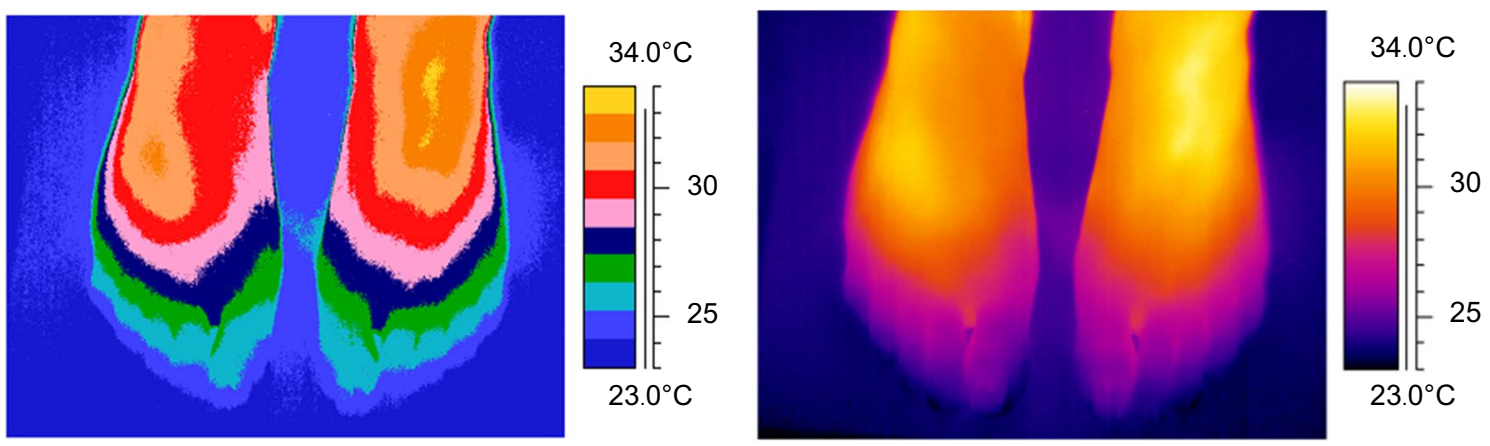

Fig. 3 Temperature distribution in the medical and standard palette of the healthy foot 
In addition, images were analyzed with a medical palette. We focused on the temperature distributions and presence of different kinds of hot spots, spikes, and gradation of the temperatures above the joints. Examples of the temperature distribution of the feet are shown in Figs. 2 and 3.

\section{Statistical analysis}

Statistical analysis was performed using the Statistica 1.0 software package. The values are presented as means with standard deviations (SDs) and medians with interquartile ranges. The Shapiro-Wilk test was used to verify the hypothesis of a distribution of the analyzed variables. Temperature differences between the determined ROIs were measured by the Wilcoxon test, whereas the correlations between the variables for all participants were assessed using the Spearman rank test. The hypotheses were verified at the level of $p<0.05$.

\section{Results}

The characteristics of the subjects in the two groups are shown in Table 1.

The study group did not differ from each other in terms of age and disease duration. In the control group, these variables were not analyzed because these participants were considered to be healthy.

There were no statistically significant differences between the average temperatures in left and right foot in any of the
Table 1 Baseline characteristics of the 81 patients with rheumatoid arthritis and 39 control group participants

\begin{tabular}{llll}
\hline & $\begin{array}{l}\text { Study group } N 81 \\
\bar{x} \pm S D \\
\left(M e ; Q_{1} \div Q_{3}\right)\end{array}$ & $\begin{array}{l}\text { Control group } N 39 \\
\bar{x} \pm S D \\
\left(M e ; Q_{1} \div Q_{3}\right)\end{array}$ & $P .0000^{*}$ \\
\hline Age (years) & $\begin{array}{l}57.4 \pm 10.47 \\
(58 ; 50 \div 65)\end{array}$ & $\begin{array}{l}21.6 \pm 1.58 \\
(21 ; 20 \div 23)\end{array}$ & NA \\
Disease duration (years) & $\begin{array}{l}13.1 \pm 9.51 \\
(10 ; 6 \div 20)\end{array}$ & NA \\
Number of inflamed joints detected & $183(22.59 \%)$ & NA \\
by ultrasonography & $235(29.01 \%)$ & NA & \\
Number of painful joints & $67(8.27 \%)$ & & \\
Number of swollen joints & &
\end{tabular}

All data are expressed as mean \pm SD (median; interquartile range) and percentages

$N A$ not analyzed

Significance at $p<0.05$

Table 2 Comparison of the average temperatures from the designated ROIs in the study and control group

\begin{tabular}{|c|c|c|c|c|c|c|c|c|}
\hline & $\begin{array}{l}\text { Study group } \\
\text { Right foot }\end{array}$ & $\begin{array}{l}(N 81) \\
\text { Left foot }\end{array}$ & $p$ & $\begin{array}{l}\text { Control group } \\
\text { Right foot }\end{array}$ & $\begin{array}{l}(N \text { 39) } \\
\text { Left foot }\end{array}$ & $p$ & $\begin{array}{l}\text { Right foot } \\
\text { pp }\end{array}$ & $\begin{array}{l}\text { Left foot } \\
\text { pp }\end{array}$ \\
\hline $\begin{array}{l}\text { Large area } \\
\text { ROI } 1\end{array}$ & $\begin{array}{l}30.98 \pm 1.82 \\
(31.2 ; 29.9 \div 32.4)\end{array}$ & $\begin{array}{l}31.04 \pm 1.93 \\
(31.4 ; 30 \div 32.5)\end{array}$ & 0.7389 & $\begin{array}{l}29.54 \pm 1.84 \\
(29.1 ; 28 \div 30.8)\end{array}$ & $\begin{array}{l}29.64 \pm 1.79 \\
(29.4 ; 28.3 \div 30.5)\end{array}$ & 0.1454 & $0.0001 *$ & $0.0001 *$ \\
\hline $\begin{array}{l}\text { Small area } \\
\text { ROI } 2\end{array}$ & $\begin{array}{l}31.40 \pm 1.69 \\
(31.55 ; 30.5 \div 32.7)\end{array}$ & $\begin{array}{l}31.44 \pm 1.81 \\
(31.75 ; 30.4 \div 32.8)\end{array}$ & 0.7554 & $\begin{array}{l}29.69 \pm 1.94 \\
(29.4 ; 28.1 \div 31)\end{array}$ & $\begin{array}{l}29.83 \pm 1.87 \\
(29.6 ; 28.4 \div 30.9)\end{array}$ & 0.2161 & $0.0000^{*}$ & $0.0000 *$ \\
\hline $\begin{array}{l}\text { MTP I } \\
\text { ROI I }\end{array}$ & $\begin{array}{l}31.13 \pm 1.87 \\
(31.4 ; 30 \div 32.5)\end{array}$ & $\begin{array}{l}31.11 \pm 1.97 \\
(31.35 ; 30 \div 32.5)\end{array}$ & 0.9840 & $\begin{array}{l}29.12 \pm 1.96 \\
(28.5 ; 27.7 \div 30.7)\end{array}$ & $\begin{array}{l}29.34 \pm 1.94 \\
(28.9 ; 27.8 \div 30.6)\end{array}$ & 0.0619 & $0.0000 *$ & $0.0000^{*}$ \\
\hline $\begin{array}{l}\text { MTP II } \\
\text { ROI II }\end{array}$ & $\begin{array}{l}31.51 \pm 1.78 \\
(31.7 ; 30.5 \div 32.7)\end{array}$ & $\begin{array}{l}31.6 \pm 1.92 \\
(32 ; 30.6 \div 33)\end{array}$ & 0.6036 & $\begin{array}{l}29.56 \pm 2.22 \\
(29.2 ; 27.9 \div 31.1)\end{array}$ & $\begin{array}{l}29.67 \pm 2.1 \\
(29.3 ; 28.1 \div 31.2)\end{array}$ & 0.3793 & $0.0000 *$ & $0.0000 *$ \\
\hline $\begin{array}{l}\text { MTP III } \\
\text { ROI III }\end{array}$ & $\begin{array}{l}31.71 \pm 1.69 \\
(31.8 ; 30.6 \div 32.8)\end{array}$ & $\begin{array}{l}31.8 \pm 1.88 \\
(32.1 ; 30.7 \div 33.3)\end{array}$ & 0.5061 & $\begin{array}{l}30.00 \pm 2.08 \\
(29.7 ; 28.3 \div 31.7)\end{array}$ & $\begin{array}{l}29.96 \pm 1.99 \\
(29.8 ; 28.5 \div 31.2)\end{array}$ & 0.8443 & $0.0000 *$ & $0.0000^{*}$ \\
\hline $\begin{array}{l}\text { MTP IV } \\
\text { ROI IV }\end{array}$ & $\begin{array}{l}31.44 \pm 1.67 \\
(31.6 ; 30.6 \div 32.8)\end{array}$ & $\begin{array}{l}31.5 \pm 1.85 \\
(31.8 ; 30.5 \div 32.8)\end{array}$ & 0.6596 & $\begin{array}{l}30.02 \pm 1.92 \\
(29.7 ; 28.6 \div 31.4)\end{array}$ & $\begin{array}{l}29.94 \pm 1.9 \\
(29.5 ; 28.6 \div 31)\end{array}$ & 0.6207 & $0.0001 *$ & $0.0000^{*}$ \\
\hline $\begin{array}{l}\text { MTP V } \\
\text { ROI V }\end{array}$ & $\begin{array}{l}30.68 \pm 1.69 \\
(30.80 ; 29.8 \div 32)\end{array}$ & $\begin{array}{l}30.78 \pm 1.77 \\
(31.05 ; 30 \div 32.1)\end{array}$ & 0.5805 & $\begin{array}{l}29.34 \pm 1.8 \\
(29 ; 27.9 \div 30.5)\end{array}$ & $\begin{array}{l}29.33 \pm 1.8 \\
(28.7 ; 28.1 \div 30.3)\end{array}$ & 0.9249 & $0.0001 *$ & $0.0000^{*}$ \\
\hline
\end{tabular}

All data are expressed as mean \pm SD (median; interquartile range)

$p$ right foot vs left foot; $p p$ study group vs control group

Significance at $p<0.05$ 
designated regions in the study and control group. However, significant differences in the average temperatures were detected between the study group and the control group (Table 2).

There was a significant difference in the average temperatures of ROI 1 and 2 of the right and left foot (Table 3).

There were no significant differences between inflamed joint temperatures that were detected by ultrasonography and joint temperatures without inflammation (right foot ROI II-V and left foot ROI I, III-V). However, the average temperature of the MTP I joint with inflammation in the right foot was significantly higher than that of MTP I without inflammation; moreover, the average temperature of inflamed MTP II

Table 3 Comparison of the average temperatures in the large and small area of the right and left foot in study group

\begin{tabular}{llll}
\hline $\begin{array}{l}\text { Study group }(N \\
81)\end{array}$ & Large area ROI 1 & Smal area ROI 2 & $p$ \\
\hline Right foot & $30.98 \pm 1.82$ & $31.40 \pm 1.69$ & $0.0000^{*}$ \\
& $(31.2 ; 29.9 \div 32.4)$ & $(31.55 ;$ & \\
& & $30.5 \div 32.7)$ & \\
Left foot & $31.04 \pm 1.93$ & $31.44 \pm 1.81$ & $0.0000^{*}$ \\
& $(31.4 ; 30 \div 32.5)$ & $(31.75 ;$ & \\
& & $30.4 \div 32.8)$ & \\
\hline
\end{tabular}

All data are expressed as mean $\pm \mathrm{SD}$ (median; interquartile range)

Significance at $p<0.05$ was statistically higher in the left foot than that of MTP II without synovitis (Table 4).

There was no correlation found between the mean temperatures of designated areas of the right and left foot and age, disease duration, the number of inflamed joints specified by ultrasound imaging, and the number of painful and swollen joints.

From the analysis of the graphical temperature distribution using a medical palette in the study group, we were unable to establish a typical image characteristic of RA. Some abnormalities have been observed in the form of hot spots, spikes, and sometimes gradation of the temperature above the joints. In contrast, in the control group, similar graphic temperature distributions in the form of a rainbow were observed, and these were manifested by a gradual decrease in the temperature from the metatarsus to the fingers. While in five people (12.8\%), the fingers were just as hot as the proximal part of the foot.

\section{Discussion}

Imaging heat radiation in the form of differences in the temperature distribution on the surface of the skin and the tissues situated deep in the body can provide information about the pathological changes [21, 24]. Registered temperature

Table 4 Baseline characteristics of the average temperatures from the selected areas in I-V MTP joints of the right and left foot with (1) and without inflammation (0) in study group

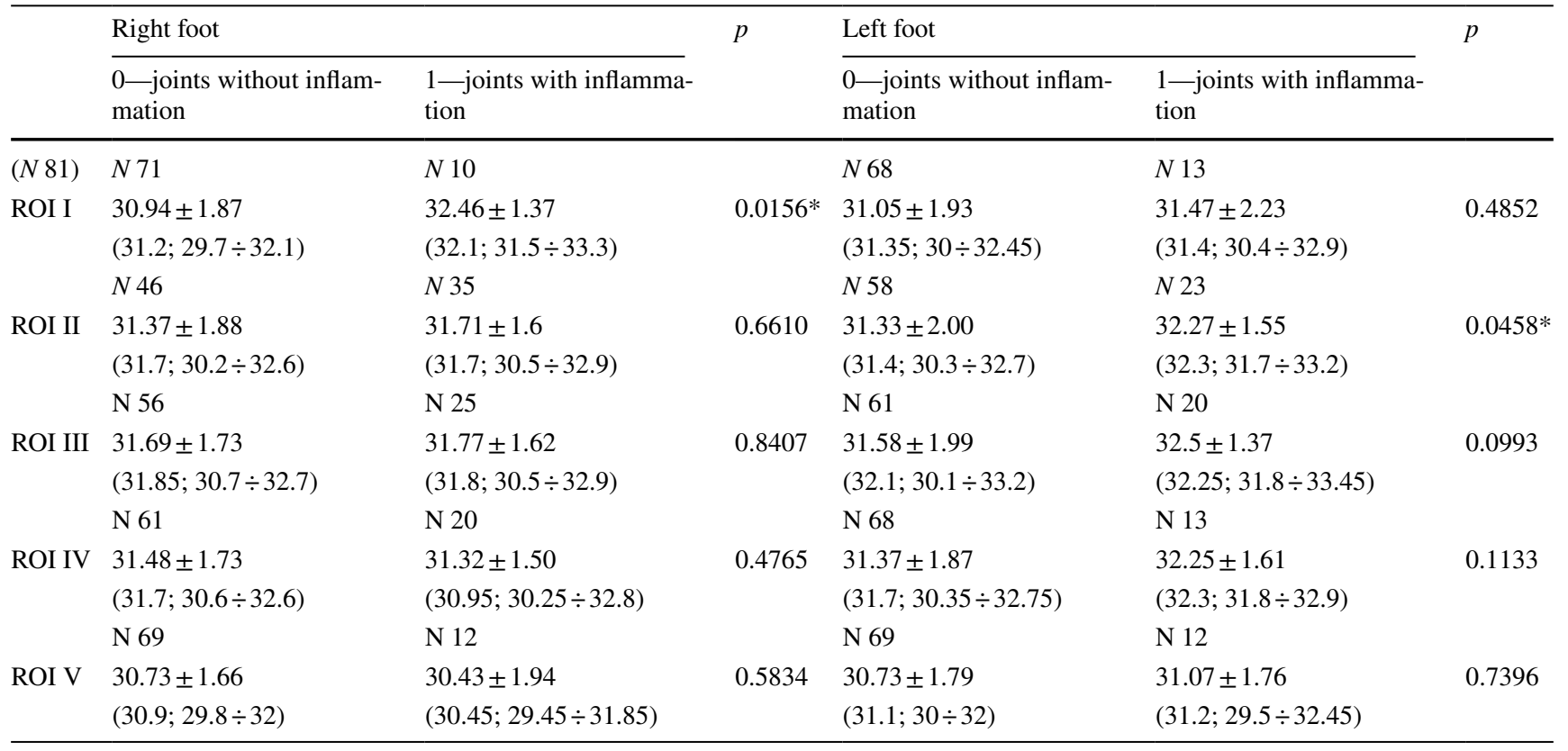

All data are expressed as mean \pm SD (median; interquartile range)

Significance at $p<0.05$ 
changes are shown in the form of hot spots or areas of inhomogeneity in the curves [15].

Several authors have dealt with the possibility of using a thermal imaging camera in the diagnosis of inflammatory conditions in locomotion organ diseases. For example, Lasanen et al. [28] demonstrated the usefulness of the thermovision method in locating inflammation in the ankle joints in RA children. Salisbury et al. [29] and Denoble et al. [9] previously described an improved sensitivity for the detection of knee joint. Studies by Umapathy et al. [30], Frize et al. [31], or Borojević et al. [32] reported the suitability of the thermovision method in locating inflammation in the joints of small hands. However, there are no studies on the use of foot thermography in rheumatology.

In our opinion, this is the first study that is comparing the temperature distribution in the rheumatoid feet and inflammation, which is located by using ultrasonography. Our study did not confirm an association between the results of the ultrasonography with the average temperatures of designated thermographic areas. Image analysis was confirmed by the temperatures observed in the study group. The joints with inflammation in the study group compared to joints without inflammation showed a significant difference in ROI I of the right foot and ROI II of the left foot.

There was no statistical difference between the remaining MTP joints. Interesting is the difference in temperature between the study group and the control group. Patients with RA had a higher average surface temperature measured in all studied areas. This fact is explained by the active disease process, which is a characteristic symptom for RA, However, it should also be noted that the groups differed in terms of age. Moreover, in our research, due to large warming signals resulting from the blood vessels in the metatarsus as well as the cooling of the distal surface, the small area ROI 2 outline and the outlines of individual joints ROI I-V seem to be the most favorable for the assessment.

Lasanen et al. [28] hypothesized that thermal imaging can detect joint inflammation in patients with juvenile idiopathic arthritis or autoimmune disease with arthritis such as systemic lupus erythematosus. The authors compared ultrasonography of ankle and knee joints with the results obtained by thermography and found that the temperatures were significantly higher in inflamed ankle joints, but for knee joints, results were inconclusive. As a consequence, it was stated that thermal imaging may have the potential for detecting joint inflammation in ankle joints of children.

Szentkuti et al. [33] reported that diagnostic infrared imaging cannot be directly compared with ultrasound imaging and other structural imaging methods because it is a functional method for analyzing physiological processes associated with the maintenance of homeostasis and organ temperature. However, it should be noted that medical diagnosis consists of both the functional and structural data of analyzed tissues.

Moreover, in our study group, the measured superficial temperature was not different in the joints diagnosed with inflammation and joints without inflammation. The reason underlying this observation is not known but Ammer et al. [34] proposed that this may be due to a reduced range of motion in the joints caused by inflammation or pain.

Studies have also compared other imaging methods. Rajapakse et al. [35] suggested that thermal images were suitable for the detection of inflammation in the knee, ankles and elbows, but not for the quantification of inflammatory processes in the small joints of the hand where smaller differences were noted between the inflamed and non-inflamed joints. We suggest that the joints in the foot are also small like in the hand, and in our study, similar outcome was observed.

Varju et al. [15] compared thermographic and radiographic diagnostic methods and found that the superficial temperature of arthritis can complement a radiographic image of the progression of osteoarthritis by providing information on the inflammatory process and the evolution of disease. In this study, a significant decline in temperature was observed with increasing severity of the disease, which might be explained by a small amount of the symptoms that were reported by patients with hand osteoarthritis and could have been caused by a concomitant disease.

While Denoble et al. [9] compared two diagnostic methods, they stated that the skin temperature of the patellar region correlated with X-ray scans showing the severity of knee osteoarthritis. They confirmed the reliability of thermal imaging as an objective method of measuring inflammation, closely associated with the destruction of the joint.

Based on the assumption that early detection minimizes the progression of disease, Suma et al. [36] correlated clinical and functional assessments with infrared thermal imaging and color Doppler ultrasound. Both methods presented a better diagnostic potential in detecting early stages of RA but infrared thermography correlated well with the clinical findings than color Doppler ultrasound.

Frize's et al. [37] compared superficial temperatures of the joints of the hands, wrists, palms, and knees of healthy participants and patients with RA. The authors proved the applicability of infrared thermal imaging to determine the presence of RA in the metacarpophalangeal (MCP) joint of the index and middle fingers and the knee. In our studies, like Frize et al. [37], at the image analysis stage, some abnormalities were observed in the form of spikes and uneven gradation of the temperatures above the joints, which are probably related to the pathophysiology of the disease. The hot spots appear to be the consequence of increased vascularity caused by synovitis and increased production of chemical inflammatory mediators [37]. On the other 
hand, the temperature of joints with proven inflammation, but which are not visible in the infrared images, could be isolated by synovial hyperplasia. This condition can also be explained by the exacerbation and remission of the disease.

In our studies, there was no relationship between ultrasound examination and temperatures observed in the thermovision.

Moreover, we have identified a normal superficial temperature distribution in healthy feet. The control group consisted of healthy individuals who we assumed had no inflammation in the joints, and thus representing the normal thermal pattern. The temperature decreased from the proximal to the distal part of the foot. In the thermovision image, the graphic temperature distribution in the form of a rainbow was observed. It was observed that the temperature in the control group was significantly lower than in the group of patients with RA, which is consistent with the theory of inflammation generating an increase in temperature [37]. Additionally, the normal heat distribution differed from the temperature distribution of patients with RA. From the thermovision images of the research group, the thermal distribution characteristic was not determined due to the lack of common characteristic features in the screening, probably caused by the complexity of the RA symptoms.

Umapathy et al. [30] measured average skin surface temperature in the MCP and proximal interphalangeal joints (PIP) in RA patients. The results of the second and third MCP joints were significantly higher than those measured in normal subjects. There were significant temperature differences between healthy subjects and patients for every joint and hand portion also found in Frize et al.'s study [31]. It is worth adding that these were preliminary studies on a small group of people.

Borojević et al. [32] also presented thermal imaging as a potential way to distinguish healthy people from those with RA or with osteoarthritis from each other. In this study, no statistically significant difference was found between the surface temperature of the right and left side of the body. However, a significant difference in mean temperature of finger and MCP joint was found. In our study, we also observed differences when looking at the distal and proximal part of the foot.

Similar to that reported by Frize et al. [37], result hot spots and cone infiltrates were observed in RA patients with inflammation or joint swelling in our study.

Salisbury et al. [29] discussed the difficulty in distinguishing normal values from pathological values due to various individual, physiological, diurnal, circadian, and environmental factors affecting the skin. In these studies, a normal distribution pattern around the knee was shown and hot spots in inflammatory joints have been characterized. The same observation was found in our research.
Sun et al. [23] found that at-risk diabetes participants have significantly higher mean foot temperature $\left(30.2 \pm 1.3{ }^{\circ} \mathrm{C}\right)$ compared to the normal subjects $\left(26.8 \pm 1.8^{\circ} \mathrm{C}\right)$. The authors explained this observation through thermoregulatory sweating disorder, which signifies early sympathetic damages in the diabetic feet.

Other authors, for example, Cholewka et al. [38, 39] observed an enhancement of the profile of skin temperature due to body cooling, which resulted in an increase in the diagnostic sensitivity of thermovision and this has potential diagnostic value in the case of spinal diseases. Lowering the temperature observed after cold application causing a bigger differentiation of the body surface temperature.

Thermal imaging not only allows to see a single point on the surface of the skin, but also the temperature of the contoured area. In addition, you can analyze the image as a whole using various medical palettes [40].

Due to the complex nature of RA, it is thus based largely on the symptoms of the disease, and therefore, there is a need to supplement the clinical diagnostic methods with additional information [41]. Thermovision may be a verification method supporting diagnosis and also clinical and functional follow-up of the patients [42], but in our opinion only in the case of a screening-based study.

There are some limitations of the study. First, the conditions, body temperature, and pre-test behavior may influence the thermovision results. Second, the control group significantly differed from the study group with respect to age. At the same time, it should be mentioned that it would be difficult to analyze a homogeneous group with respect to patients with RA due to various degenerative changes in the feet, which are the result of progressive degenerative conditions and accompanying underlying diseases.

\section{Conclusions}

Thermal imaging has been used as a supporting method in the diagnosis and assessment of medical improvement after treating many diseases. The present study attempted to use thermal imaging in the evaluation of inflammatory changes within the rheumatoid foot. Significant differences in average foot temperatures were detected between the study group and the control group. At the same time, there were no statistically significant differences between the average temperatures in the left and right foot in any of the designated regions within the study and control groups. Reliability of comparison of the ultrasonography results and different parameters in thermal imaging were not confirmed in our study. The comparison of average temperatures of joints with or without inflammation, according to ultrasonography, 
did not show significance except for two joints. However, we observed changes in the form of spikes, hot spots, and gradation of temperature during screening using a medical palette. These changes in the thermal map may suggest a pathological process in the feet of RA patients and require deeper analysis. Observation of the image as a whole and analysis of the temperature distribution of the examined body parts can aid in the diagnosis of RA and the evaluating the development of the disease. Additional research must be conducted to confirm the results of this study.

\section{Compliance with ethical standards}

Conflict of interest All authors declare that they have no conflicts of interest.

Ethical approval All procedures performed in studies involving human participants were in accordance with the ethical standards of the institutional and/or national research committee and with the 1964 Helsinki declaration and its later amendments or comparable ethical standards.

Informed consent Informed consent was obtained from all individual participants included in the study.

Open Access This article is licensed under a Creative Commons Attribution 4.0 International License, which permits use, sharing, adaptation, distribution and reproduction in any medium or format, as long as you give appropriate credit to the original author(s) and the source, provide a link to the Creative Commons licence, and indicate if changes were made. The images or other third party material in this article are included in the article's Creative Commons licence, unless indicated otherwise in a credit line to the material. If material is not included in the article's Creative Commons licence and your intended use is not permitted by statutory regulation or exceeds the permitted use, you will need to obtain permission directly from the copyright holder. To view a copy of this licence, visit http://creativecommons.org/licenses/by/4.0/.

\section{References}

1. Aletaha D, Neogi T, Silman AJ, Funovits J, Felson DT, Bingham $\mathrm{CO}$, et al. Rheumatoid arthritis classification criteria. Arthritis Rheum. 2010;62:2569-81.

2. Majithia V, Geraci SA. Rheumatoid arthritis: diagnosis and management. Am J Med. 2007;120(11):936-9.

3. Bax M, van Heemst J, Huizinga TW, Toes RE. Genetics of rheumatoid arthritis: what have we learned? Immunogenetics. 2011;63(8):459-66.

4. Van der Leeden M, Steultjens M, Dekker JHM, Prins APA, Dekker J. Forefoot joint damage, pain and disability in rheumatoid arthritis patients with foot complaints: the role of plantar pressure and gait characteristics. Rheumatology. 2006;45(4):465-9.

5. Wiener-Ogilvie S. The foot in rheumatoid arthritis. The Foot. 1999;9(4):169-74.

6. Cholewka A, Knefel G, Stanek A, Kawecki M, Nowak M, Sieroń A, Drzazga Z. Thermal imaging and TC oximetry measurements of hyperbaric oxygen therapy (HBO) effects on trophic ulceration of the crura. J Therm Anal Calorim. 2012;108:25-31.
7. Cholewka A, Kajewska J, Kawecki M, Sieron-Stoltny K, Stanek A. How to use thermal imaging in venous insufficiency? J Therm Anal Calorim. 2017;130(3):1317-26.

8. Glik J, Cholewka A, Englisz B, Stanek A, Sieroń K, MikuśZagórska K, Knefel G, Nowak M, Kawecki M. Thermal imaging and planimetry evaluation of the results of chronic wounds treatment with hyperbaric oxygen therapy. Adv Clin Exp Med. 2019;28(2):229-36.

9. Denoble AE, Hall N, Pieper CF, Kraus VB. Patellar skin surface temperature by thermography reflects knee osteoarthritis severity. Clin Med Insights Arthritis Musculoskelet Disord. 2010;3:69-75.

10. Ring EFJ, Ammer K. Infrared thermal imaging in medicine. Physiol Meas. 2012;33:33-46.

11. Bauer J, Dereń E. Standaryzacja badań termograficznych w medycynie i fizykoterapii. Inż Biomed. 2014;20(1):11-20.

12. Ring EFJ, Collins AJ, Bacon PA, Cosh JA. Quantitation of thermography in arthritis using multi-isothermal analysis II. Effect of nonsteroidal anti-inflammatory therapy on the thermographic index. Ann Rheum Dis. 1974;33:353-6.

13. Jones BF. A reappraisal of the use of infrared thermal image analysis in medicine. IEEE Trans Med Imaging. 1998;17(6):1019-27.

14. Haake M, Willenberg T, Sauer F, et al. Effect of extracorporeal shockwave therapy on vascular regulation. Infrared thermography in epicondylitis humeri radialis. Swiss Surg. 2002;8:176-80.

15. Varju G, et al. Assessment of hand osteoarthritis: correlation between thermographic and radiographic methods. Rheumatology. 2004;43(7):915-9.

16. Zaproudina N, Ming Z, Hänninen POO. Plantar infrared thermography measurements and low back pain intensity. J Manip Physiol Ther. 2006;29:219-22.

17. Korman P, Straburzynska-Lupa A, Romanowski W, Trafarski A Temperature changes in rheumatoid hand treated with nitrogen vapors and cold air. Rheumatol Int. 2012;32:2987-92. https://doi. org/10.1007/s00296-011-2078-5.

18. Rutkowski R, Straburzyńska-Lupa A, Korman P, Romanowski W, Gizińska M. Thermal effectiveness of different IR radiators employed in rheumatoid hand therapy as assessed by thermovisual examination. Photochem Photobiol. 2011;87(6):1442-6.

19. Anderson ME, Moore TL, Lunt M, Herrick AL. The 'distal-dorsal difference': a thermographic parameter by which to differentiate between primary and secondary Raynaud's phenomenon. Rheumatology (Oxford). 2007;46(3):533-8.

20. Foerster J, Kuerth A, Niederstrasser E, Krautwald E, Pauli R, Paulat R, Eweleit M, Riemekasten G, Worm M. A cold-response index for the assessment of Raynaud's phenomenon. J Dermatol Sci. 2007;45(2):113-20.

21. $\mathrm{Ng}$ EK. A review of thermography as promising non-invasive detection modality for breast tumor. Int $\mathbf{J}$ Thermal Sci. 2009;48(5):849-59.

22. Hayase Y, Wakasa T, Uemura M, Adachi K, Ochi S, Kishi K. Clinical evaluation of thermography in the diagnosis of malignant tumors in the oral and maxilla-facial region. Oral Radiol. 1992;8(1):11-7.

23. Sun P, Lin H, Jao SE, Ku Y, Chan R, Cheng CK. Relationship of skin temperature to sympathetic dysfunction in diabetic at-risk feet. Diabetes Res Clin Pract. 2006;73:41-6.

24. Seixas A, Azevedo J, Pimenta I, Ammer K, Carvalho R, VilasBoas JP, et al. Skin temperature of the foot: reliability of infrared image analysis based in the angiosome concept. Infrared Phys Technol. 2018;92:402-8.

25. Szkudlarek M, Court-Payen M, Jacobsen S, Klarlund M, Thomsen HS, Ostergaard M. Interobserver agreement in ultrasonography of the finger and toe joints in rheumatoid arthritis. Arthritis Rheum. 2003;48:955-62.

26. Scheel AK, Herman KG, Kahler E, Pasewaldt D, Fritz J, Hamm B, et al. A novel ultrasonographic synovitis scoring system suitable 
for analyzing finger joint inflammation in rheumatoid arthritis. Arthritis Rheum. 2005;52(3):733-43.

27. Ammer K. The Glamorgan Protocol for recording and evaluation of thermal images of the human body. Thermol Int. 2008; 18:125-44.

28. Lasanen R, Piippo-Savolainen E, Remes-Pakarinen T, et al. Thermal imaging in screening of joint inflammation and rheumatoid arthritis in children. Physiol Meas. 2015;36:273-82.

29. Salisbury RS, Parr G, De Silva M, Hazleman BL, Page-Thomas DP. Heat distribution over normal and abnormal joints: thermal pattern and quantification. Ann Rheum Dis. 1983;42(5):494-9.

30. Umapathy S, Vasu S, Gupta N. Computer aided diagnosis based hand thermal image analysis: a potential tool for the evaluation of rheumatoid arthritis. J Med Biol Eng. 2017. https://doi. org/10.1007/s40846-017-0338-x.

31. Frize M, Karsh J, Herry C, Adéa C, Aleem C, Payeur P. Preliminary results of severity of illness measures of rheumatoid arthritis using infrared imaging. Proc. MeMeA (Medical Measurements and Applications), Cetraro, Italy. May 2009, pp. 187-192.

32. Borojević N, Kolarić D, Grazio S, Grubišić F, Antonini S, Nola IA, Herceg Ž. Thermography hand temperaturę distribution in rheumatoid arthritis and osteoarthritis. Period Biol. 2011;113(4):445-8.

33. Szentkuti A, Kavanagh HS, Grazio S. Infrared thermography and image analysis for biomedical use. Period Biol. 2011;113:385-92.

34. Ammer K. Low muscular activity of the lower leg in patients with a painful ankle. Thermol Österr. 1995;5:103-7.

35. Rajapakse C, Grennan DM, Jones C, Wilkinson L, Jayson M. Thermography in the assessment of peripheral joint inflammation-a re-evaluation. Rheumatology. 1981;20(2):81-7.
36. Suma AB, Snekhalatha U, Rajalakshmi T. Evaluation of rheumatoid arthritis using thermography and colour Doppler ultrasound. IJCTA. 2016;9(37):443-52.

37. Frize M, Adéa C, Payeur P, Di Primio G, Karsh J, Ogungbemile A. Detection of rheumatoid arthritis using infrared imaging, Proc. SPIE 7962, Medical Imaging International Society for Optics and Photonics 2011:79620.

38. Cholewka A, Drzazga Z, Sieroń A, Stanek A. Thermovision diagnostics in chosen spine diseases treated by whole body cryotherapy. J Therm Anal Calorim. 2010;102(1):113-9.

39. Cholewka A, Stanek A, Wojcik M, Sieron-Stoltny K, Drzazga Z. Does local cryotherapy improve thermal diagnosis similar to whole-body cryotherapy in spinal diseases? J Therm Anal Calorim. 2017;127(2):1155-62.

40. Ivanitskii GR. Thermovision in medicine. Herald Russ Acad Sci. 2006;76(1):44-53.

41. de Silva M, Kyle V, Hazleman B, Salisbury R, Page Thomas P, Wraight $P$. Assessment of inflammation in the rheumatoid knee joint: correlation between clinical, radioisotopic, and thermographic methods. Ann Rheum Dis. 1986;45:277-80.

42. Calin MA, Mologhianu G, Savastru R, Calin MR, Brailescu CM. A review of the effectiveness of thermal infrared imaging in the diagnosis and monitoring of knee diseases. Infrared Phys Technol. 2015;69:19-25.

Publisher's Note Springer Nature remains neutral with regard to jurisdictional claims in published maps and institutional affiliations. 